\title{
Melatonin and Its Day and Night Rhythm of Alterations in Familial Mediterranean Fever: A Brief Research Letter
}

\author{
Ugur Musabak $^{*}, 1$, Guldem Kilciler ${ }^{2}$, Ahmet Uygun $^{2}$, Murat Kantarcıoglu², Zulfukar Polat ${ }^{2}$, \\ Rahsan I. Sagkan ${ }^{1}$ and Sait Bagci ${ }^{2}$ \\ ${ }^{I}$ Department of Immunology, Gulhane Military Medical Academy and School of Medicine, 06018 Etlik, Ankara, Turkey \\ ${ }^{2}$ Department of Gastroenterology, Gulhane Military Medical Academy and School of Medicine, 06018 Etlik, Ankara, \\ Turkey
}

\begin{abstract}
Objective: The pineal hormone melatonin plays a crucial role in immunomodulation, mainly by effecting T cells. The aims of the present study were to compare the melatonin levels in patients with Familial Mediterranean Fever (FMF) and healthy controls and to find out if it associates with interferon(IFN)y and interleukin(IL)-10.

Materials and Methodology: Twenty five patients with FMF and 16 healthy donors were enrolled into the study. Melatonin, IFN $\gamma$ and IL-10 measurements were assayed by using enzyme immunoassay (EIA) method.

Results: Serum melatonin levels at $03.30 \mathrm{am}$ in both patients during attack-free phase and healthy controls were significantly higher than those levels of corresponding groups measured at $10.00 \mathrm{am}$. The melatonin levels at 03.30 and $10.00 \mathrm{am}$ in patients during attack-free phase were higher than those levels measured in healthy controls at the same time points. IFN $\gamma$ and IL-10 did not show any day and night rhythm in both patients and healthy controls. In addition, there was no association among day and night levels of melatonin, IFN $\gamma$ and IL-10.

Conclusions: We conclude that melatonin may play a role in FMF pathogenesis. However, its modulatory effect on immune response most likely does not depend on $\mathrm{T}$ cells. Further comprehensive studies should be performed in order to reveal the role of melatonin in the pathogenesis of this disease.
\end{abstract}

Keywords: Familial Mediterranean fever, melatonin, interferon, interleukin.

\section{INTRODUCTION}

Familial Mediterranean Fever (FMF) is a systemic relapsing autoinflammatory disorder occurring in populations originating from the Mediterranean basin, mainly Turks, Levantine Arabs, Sephardic Jews, Druze and Armenians [1, 2]. The most characteristic clinical manifestation of the disease is periodic attacks of fever accompanied by serosal membrane inflammation at the affected sites such as peritoneum, pleura or synovium, with a massive influx of polymorphonuclear neutrophils [3]. The gene causing FMF, MEFV, is localized to chromosome $16 \mathrm{p} 13$, and its mutations cause the autoinflammatory phenotype of FMF [4].

Previously, some immunological abnormalities including impaired production of proinflammatory cytokines such as tumor necrosis factor(TNF) $\alpha$, interleukin(IL)-1 and IL-6 have been reported in FMF [5-9]. These findings support that FMF is a disease of the innate immune system. However, the two branches of the adaptive immune system, B cells and $\mathrm{T}$ cells, seem to contribute to the disease pathogenesis by mainly their secretory products [9-11].

*Address correspondence to this author at the Department of Immunology, Gulhane Military Medical Academy and School of Medicine, 06018 Etlik, Ankara, Turkey; Tel: +90 31230443 41; Fax: +90 31230420 40;

E-mail: umusabak@hotmail.com
It is well known that $\mathrm{T}$ helper (Th) cell populations are subdivided into two different types based on the cytokines they secrete $[12,13]$. Th1 type cells heavily produce inflammatory cytokine interferon(IFN) $\gamma$, while Th2 type cells heavily produce anti-inflammatory cytokine IL-4. It was previously reported that Th1/Th2 balance may exhibit diurnal rhythmicity in healthy humans, and melatonin may regulate diurnal variation in IFN $\gamma /$ IL-10 ratio [14]. The pineal hormone melatonin is involved in the regulation of circadian rhythm, and its production is highest at night. It was shown that melatonin has specific binding sites on both Th1 and Th2 cells, which enhance Th cell activity by increasing IL-2 production $[15,16]$. Melatonin also stimulates IL-12 production by monocytes driving $\mathrm{T}$ cell differentiation toward the Th1 type and causing an increase in IFN $\gamma$ production [17].

We previously showed that the CD4+ Th cells are abnormally activated in patients with FMF in both the attack and the attack-free phases, and that decreased IL-10 levels may create a tendency to perpetuate subclinical immune activation in the attack phase [18]. Therefore, in the present study, we aimed to determine whether serum melatonin concentrations are associated with FMF and serum IFN $\gamma$ and IL-10 levels.

\section{MATERIALS AND METHODOLOGY}

\section{Patients}

Twenty five patients with FMF (20 male, 5 female) and 16 sex- and age-matched healthy volunteers (13 male, 3 
female) were enrolled into the study. None of the patients with FMF had an immunological disorder or another rheumatic disease. The clinical diagnosis of FMF was based on the Tel-Hashomer criteria [19]. Attack-free phases (defined as being free of attacks for at least 3 weeks) and acute phases were determined based on clinical (fever, abdominal pain, arthritis) and laboratory findings [high levels of fibrinogen, white blood cell (WBC) count and erythrocyte sedimentation rate (ESR)]. All patients were evaluated during both the attack-free and the attack phases. The immunological parameters of patients with active clinical presentations were measured within the first $48 \mathrm{~h}$ following onset of the attack. This study was conducted in conformity to the Helsinki Declaration and approved by our local research ethics committee.

Ten milliliters of venous blood was drawn from the patients in attack-free phase and healthy controls at $03.30 \mathrm{am}$ and $10.00 \mathrm{am}$ and centrifuged at 3000 r.p.m. for $30 \mathrm{~min}$ for the measurements of melatonin, IFN $\gamma$ and IL-10 levels. The blood was also collected from the patients in attack phase at $10.00 \mathrm{am}$ for determining the same parameters. The specimens were stored at $-20^{\circ} \mathrm{C}$ until analysis.

\section{Laboratory Analyses}

White blood cell count was performed using an automated whole blood cell counter (Cell-Dyn 1700, Abbot, Santa Clara, CA, USA) and the reference range was between $3600-10000 / \mathrm{mm}^{3}$. The Westergreen method was used for ESR. Normal levels of ESR were $0-15 \mathrm{~mm} / \mathrm{hr}$ for males and $0-20 \mathrm{~mm} / \mathrm{hr}$ for females. Fibrinogen levels were measured by a photooptic method using fibrinogen reagent (Sigma Diagnostics) and an Amelung AMAX 190 Plus analyzer. Reference range of fibrinogen levels was $200-400 \mathrm{mg} / \mathrm{dl}$ according to manufacturer's instructions. All of these tests were measured in daytime (at $10.00 \mathrm{am}$ ).

\section{Measurements of Melatonin, IFN $\gamma$ and IL-10}

The levels of serum melatonin (IBL International, Hamburg, Germany) were measured by enzyme immunoassay (EIA), while IFN $\gamma$ and IL-10 (DiaSource, Nivelles, Belgium) were measured by enzyme amplified sensitivity immunoassay (EASIA). Absorbance readings were carried out on Alisei Quality System (SEAC Radim
Group, Pomezia, Italy). Serum concentrations of melatonin, IFN $\gamma$ and IL-10 were determined from a curve obtained with the standards. According to manufacturer instructions, the detection limits of kits were $1.6 \mathrm{pg} / \mathrm{ml}$ for melatonin and IL10 , and $0.03 \mathrm{IU} / \mathrm{ml}$ for IFN $\gamma$.

\section{Statistical Analysis}

All statistical analyses were performed using a computer software (SPSS for Windows version 11.5, SPSS Inc., Chicago, IL, USA). For the tests of normality, we used Kolmogorov-Smirnov test. Independent-Samples $\mathrm{T}$ test was used for the comparisons of study groups with respect to age, body mass index (BMI), WBC counts, ESR and fibrinogen levels. The Friedman test was used for multiple statistical comparisons. The Wilcoxon test was used as a post hoc test, if the Friedman test is statistically significant. This test was also used for the comparison of two dependent groups. Mann-Whitney U test and Chi-square tests were respectively used to compare the median values of melatonin and the percentages of detectable IFN $\gamma$ levels or gender difference in the study groups. To investigate the relations among the variables, we used Pearson or Spearman's rank correlation test, whichever was appropriated. A $p$ value $<0.05$ was considered to be statistically significant.

\section{RESULTS}

The general characteristics and main laboratory parameters of the study groups were summarized in Table $\mathbf{1}$. Age, gender and body mass index (BMI) in the patients with FMF and healthy controls were not different from each other. In an attack phase, all of the 25 patients with FMF had abdominal pain (100\%), $4(16 \%)$ had pleuritic chest pain and $4(16 \%)$ had arthritis/arthralgia. Seven of the 25 patients (28\%) had a family history of FMF. Except for 6 newly diagnosed patients, all of the other 19 patients were on a continuous colchicine treatment (1-2 mg/day). WBC counts in 22 patients $(88 \%)$, ESR in 25 patients $(100 \%)$ and fibrinogen in 17 patients (68\%) in attack phases were elevated above the normal ranges of these laboratory parameters. Body temperatures increased in all patients $(100 \%)$ during attack phase.

Melatonin levels measured at 03.30 am both in patients with FMF in attack-free phase and healthy controls were

Table 1. Demographic and Main Laboratory Parameters in Patients with FMF and Healthy Controls

\begin{tabular}{|l|c|c|c|}
\hline & Patients with FMF (n=25) & Healthy Controls ${ }^{\zeta}$ (n=16) \\
\hline \hline Age (years) & \multicolumn{2}{|c|}{$21.3 \pm 1.4$} & $21.0 \pm 1.3$ \\
\hline Male/Female & \multicolumn{2}{|c|}{$20 / 5$} & $13 / 3$ \\
\hline BMI & \multicolumn{2}{|c|}{$23.7 \pm 1.5$} & in atttack-free phase ${ }^{\zeta}$ \\
\hline & in acute attack phase ${ }^{*}$ & $6156 \pm 1238$ & $6518 \pm 1395$ \\
\hline WBC $\left(\mathrm{mm}^{3}\right)$ & $10028 \pm 1997$ & $13.2 \pm 5.1$ & $13.3 \pm 5.4$ \\
\hline ESR $(\mathrm{mm} / \mathrm{hr})$ & $39.3 \pm 7.2$ & $347 \pm 70$ & $317 \pm 58$ \\
\hline Fibrinogen $(\mathrm{mg} / \mathrm{dl})$ & $400 \pm 58$ & $36.2 \pm 0.5$ & $36.2 \pm 0.7$ \\
\hline Body Temperature $\left({ }^{\circ} \mathrm{C}\right)$ & $37.7 \pm 0.6$ & & \\
\hline
\end{tabular}

The measurements were expressed in mean \pm standard deviation. Comparisons between means were made by Independent Samples T test. Chi-square test was used for gender comparison. ${ }^{*} \mathrm{P}$ values were lower than 0.05 in the comparisons between either the patients during attack and attack-free phases or patients during attack phase and healthy controls with regards to WBC, ESR, fibrinogen and body temperature. ${ }^{\zeta}$ These parameters were measured at $10.00 \mathrm{am}$. 
Table 2. Melatonin Levels in Patients with FMF and Healthy Controls

\begin{tabular}{|c|c|c|c|}
\hline \multirow{2}{*}{} & \multicolumn{3}{|c|}{ Melatonin Levels (pg/ml) $^{*}$} \\
\cline { 2 - 4 } & in Acute Attack & at 03.30 am & at 10.00 am \\
\hline \hline Patients with FMF $(\mathrm{n}=25)$ & $17.1(7.7-32.9)^{\mathrm{a}}$ & $184.5(55.9-354.8)^{\mathrm{b}}$ & $15.3(4.5-133.8)^{\mathrm{c}}$ \\
\hline Healthy Controls $(\mathrm{n}=16)$ & & $68.3(11.3-192.3)^{\mathrm{d}}$ & $6.4(5.1-9.8)^{\mathrm{e}}$ \\
\hline
\end{tabular}

The measurements were expressed in median (minimum-maximum). Comparisons between medians were made by Mann-Whitney $\mathrm{U}$ test. $\mathrm{p}<0.001 \mathrm{for} \mathrm{a} v s \mathrm{~b}, \mathrm{~b} v s \mathrm{c}, \mathrm{a} v s \mathrm{e}, \mathrm{d} v s \mathrm{e}, \mathrm{b}$ $v s \mathrm{~d}$, and $\mathrm{c} v s \mathrm{e} ; \mathrm{p}=0.543$ for a $v s \mathrm{c}$. ${ }^{*}$ Melatonin levels at $03.30 \mathrm{am}$ and $10.00 \mathrm{am}$ in patients with FMF were measured in attack-free phase.

higher than those measured at 10.00 am (Table 2, Fig. 1). While melatonin levels measured at 03.30 am in patients with FMF in attack-free phase were higher than those measured in the attack phase, there was no significant difference between melatonin levels at the two phases measured at $10.00 \mathrm{am}$. The melatonin levels of patients with FMF in attack-free phase both at 03.30 am and $10.00 \mathrm{am}$ were also higher than those the levels of healthy controls measured at the same time points.

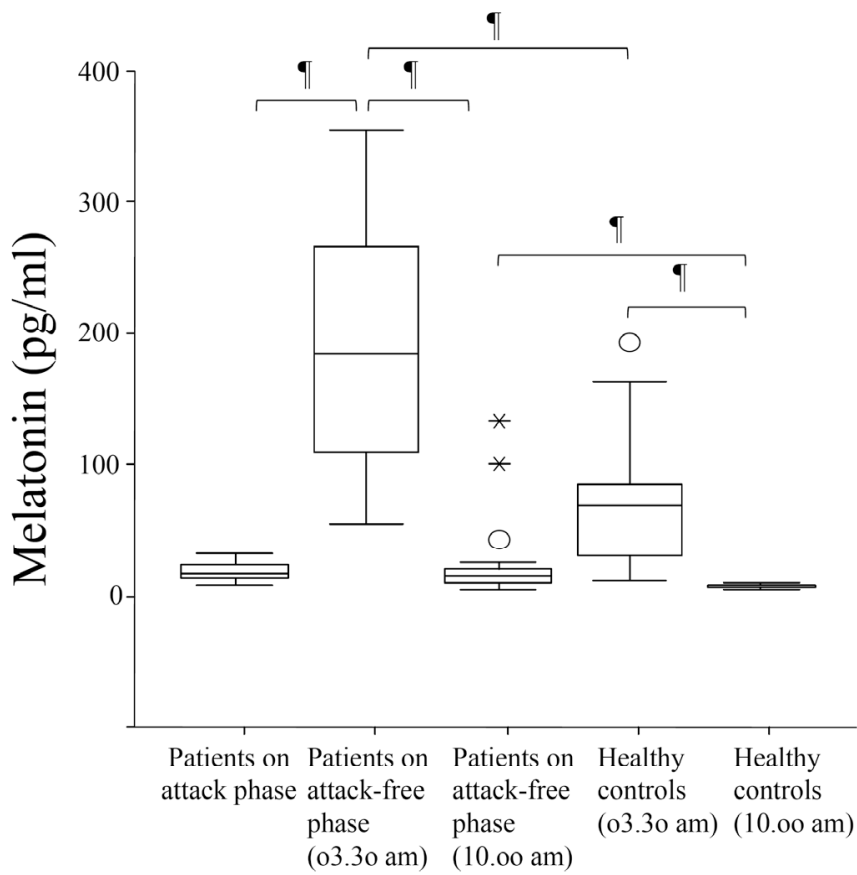

Fig. (1). Comparison of melatonin levels at different times of the day in patients with FMF and healthy controls. Boxes show the ranges of 1 st and 3rd quartiles and extreme values, with the horizontal bars representing median values. $P$-values were indicated with an asterix above the boxes when a level of significance $<0.05$ was reached in comparisons of study groups.

On the other hand, the percentage of patients with FMF who had detectable concentrations of IFN $\gamma$ in the attack phase was higher than the percentage of patients with detectable concentrations of IFN $\gamma$ in the attack-free phase at both $03.30 \mathrm{am}$ and $10.00 \mathrm{am}$. (Table 3). No significant difference at 03.30 am and 10.00 am measurements between attack-free patients and healthy controls was observed. Only 1 of the 25 patients was found to have detectable IL-10 levels in attack phase. None of the patients in attack-free phase and none of the healthy controls had detectable IL-10 levels at 03.30 am and $10.00 \mathrm{am}$.
Table 3. The Presence of IFN $\gamma$ in Patients with FMF and Healthy Controls

\begin{tabular}{|c|c|c|c|}
\hline \multirow{2}{*}{} & \multicolumn{3}{|c|}{$\begin{array}{c}\text { Individuals who had detectable IFN } \boldsymbol{\gamma}^{*} \\
\text { n (\%) }\end{array}$} \\
\cline { 2 - 4 } & in Acute Attack & at 03.30 am & at 10.00 am \\
\hline \hline Patients with FMF $(\mathrm{n}=25)$ & $20(80)^{\mathrm{a}}$ & $13(52)^{\mathrm{b}}$ & $13(52)^{\mathrm{c}}$ \\
\hline Healthy Controls $(\mathrm{n}=16)$ & & $12(75)$ & $12(75)$ \\
\hline
\end{tabular}

Comparisons between the percentages were made by chi-square test. $\mathrm{X}^{2}=4.367$; $\mathrm{p}=0.037$ for $\mathrm{a} v s \mathrm{~b}$ and a $v s \mathrm{c}$. ${ }^{*}$ The number and percentages of patients with FMF who had detectable IFN $\gamma$ at 03.30 am and 10.00 am shows the results in attack-free phase.

We didn't find any correlation among the levels of melatonin, IFN $\gamma$ and IL-10 in both patients with FMF and healthy controls. All these parameters were also not correlated with acute phase reactants such as ESR, WBC and fibrinogen levels.

\section{DISCUSSION}

Accumulated data in the literature until now suggest that melatonin has dual effect on inflammation as stimulating or inhibiting [20, 21]. These opposite actions of melatonin mainly depend on polarization of naive $T$ cells into Th1 or Th2 [22]. It seems that $T$ cells are the main target of melatonin in mice and humans $[16,22]$. In Inserra et al.'s study, it was shown that melatonin significantly increases Th1 cytokines, IL-2 and IFN-gamma, whereas significantly decreases Th2 cytokines, IL-6 and IL-10 in aged female C57BL/6 mice [23]. In contrast, Shaji et al. demonstrated that melatonin induces the Th2 like immune response by stimulating IL-4 production in mice [24]. In another study, inhibitory effect of melatonin on TNF production in mice treated with a lethal dose of lipopolysaccharide has been shown by Sacco et al. [25]. The inhibitory effect of melatonin on concanavalin A (ConA)-induced proliferative response of human peripheral blood lymphocytes was found in physiologic dose $\left(10^{-9} \mathrm{M}\right)$ in Konakchieva et al.'s study [26], whereas pharmacologic doses $(>0.20 \mathrm{mM})$ of melatonin were required to achieve inhibitory effect of melatonin on the proliferation of mitogen-stimulated human peripheral blood lymphocytes in Vijayalxmi et al.'s study [27].

The number of studies investigating the role of melatonin on the immunopathogenesis of any disease is limited in the literature. In general, these studies were done in Th1 driven diseases such as rheumatoid arthritis (RA) and multiple sclerosis (MS). In addition, until now, melatonin has not been studied in any autoinflammatory diseases. Therefore, we compared our current study results with those of the studies on autoimmune diseases. We demonstrated for the 
first time in the current study that FMF patients had higher melatonin levels at night $(03.30 \mathrm{am})$ and daytime $(10.00 \mathrm{am})$ compared to those of healthy controls. However, the serum melatonin concentration was neither correlated with IFN $\gamma$ levels, nor with IL-10 levels in FMF patients and control subjects. We also couldn't find a day and night rhythm for IFN $\gamma$ and IL-10 in our study groups.

Partially similar results were found in Sully et al.'s study in which melatonin serum levels at $8 \mathrm{pm}$ and 8 am were found to be higher in RA patients than in healthy controls [28]. However melatonin levels at 2, 4, 6 am and $12 \mathrm{pm}$ were not different from those of healthy controls. In addition, the authors proposed that the clinical symptoms of RA, such as morning gelling, stiffness, and swelling, which are more evident in the early morning, might be related to the immunomodulatory effects of melatonin on synovitis. Cutolo et al. also suggest that increased nocturnal melatonin production in RA patients seems to be an important factor in the appearance of the circadian symptoms of the disease [29]. Accordingly, in RA patients, proinflammatory Th1 type cytokine production exhibits a diurnal rhythmicity with peak levels during the night and early morning, when plasma cortisol is lowest and melatonin is highest. Haase et al. showed that serum melatonin levels in benign MS patients significantly decrease with azathioprine (AZA) treatment compared to untreated patients [30]. They suggest that immunosuppressive effect of AZA during the stabile phase of MS was largely due to decreasing melatonin production. This study also indicates that melatonin have an immunomodulatory effect in MS disease.

We could not detect any relationship between melatonin and the cytokines IFN $\gamma$ and IL-10 in FMF patients. However, we may speculate that high levels of melatonin during nighttime and day-time in the FMF patients may contribute the disease pathogenesis by stimulating other immune cells. It was formerly reported that melatonin has an activation capability on monocytes, natural killer cells, and neutrophils [29]. Especially, the studies related to the effects of melatonin on neutrophil functions may help us to understand the role of melatonin in FMF disease which is known as a neutrophil-related disease [31].

In conclusion, the immunoregulatory role of melatonin is very complex, and its mechanisms are not yet completely understood. Due to this striking feature, melatonin may be involved in immunopathogenesis of many autoimmune and autoinflammatory diseases. Our findings provide an evidence that melatonin may play a role in the immunopathogenesis of FMF. However, further comprehensive researches investigating the relationships between melatonin and immune response in FMF are needed to understand its role in the pathogenesis of this disease.

\section{REFERENCES}

[1] Ben-Chetrit E, Levy M. Familial Mediterranean fever. Lancet 1998; 351: 659-64.

[2] Orbach H, Ben-Chetrit E. Familial Mediterranean fever. Minerva Med 2001; 92: 421-30.

[3] Korkmaz C, Ozdogan H, Kasapcopur O, Yazici H. Acute phase response in familial Mediterranean fever. Ann Rheum Dis 2002; 61: 79-81.

[4] Centola M, Wood G, Frucht DM, et al. The gene for familial Mediterranean fever, MEFV, is expressed in early leukocyte development and is regulated in response to inflammatory mediators. Blood 2000; 95: 3223-31.

[5] Schattner A, Lachmi M, Livneh A, Pras M, Hahn T. Tumor necrosis factor in familial Mediterranean fever. Am J Med 1991; 90: 434-8.

[6] Ozyilkan E, Simsek H, Telatar H. Tumor necrosis factor in familial Mediterranean fever. Am J Med 1992; 92: 579-80.

[7] Rozenbaum M, Katz R, Rozner I, Pollack S. Decreased interleukin1 activity released from circulating monocytes of patients with familial Mediterranean fever during in vitro stimulation by lipopolysaccharide. J Rheumatol 1992; 19: 416-8.

[8] Akcan Y, Bayraktar Y, Arslan S, Van Thiel DH, Zerrin BC, Yildiz $\mathrm{O}$. The importance of serial measurements of cytokine levels for the evaluation of their role in pathogenesis in familial Mediterraean fever. Eur J Med Res 2003; 8: 304-6.

[9] Gang N, Drenth JP, Langevitz P, et al. Activation of the cytokine network in familial Mediterranean fever. J Rheumatol 1999; 26: 890-7.

[10] Karagezian KG, Nazaretian EE, Zavgorodniaia AM, Ovnanian KO. Immune disorders in periodic disease. Klin Med 2000; 78: 24-5.

[11] Melamed A, Cabili S, Zakuth V, Spirer Z. The immune regulation in familial Mediterranean fever. J Clin Lab Immunol 1998; 26: 125-8.

[12] Abbas AK, Murphy KM, Sher A. Functional diversity of helper T lymphocytes. Nature 1996; 383: 787-93.

[13] Xie D, Liu Z, Li Z, Ji Y, Chen J, Sun B. Differential expression of neutrophilic granule proteins between Th1 and Th2 cells. Acta Biochim Biophys Sin (Shanghai) 2007; 39: 67-72.

[14] Petrovsky N, Harrison LC. Diurnal rhythmicity of human cytokine production: a dynamic disequilibrium in $\mathrm{T}$ helper cell type 1/T helper cell type 2 balance? J Immunol 1997; 158: 5163-8.

[15] Liebmann PM, Wölfler A, Felsner P, Hofer D, Schauenstein K. Melatonin and the immune system. Int Arch Allergy Immunol 1997; 112: 203-11.

[16] Garcia-Maurino S, Gonzalez-Haba MG, Calvo JR, et al. Melatonin enhances IL-2, IL-6 and IFN $\gamma$ production by human circulating CD4+ cells: A posible nuclear receptor-mediated mechanism involving T helper type 1 lymphocytes and monocytes. J Immunol 1997; 159: 574-81.

[17] Garcia-Maurino S, Pozo D, Carrillo-Vico A, Calvo JR, Guerrero JM. Melatonin activates Th1 lymphocytes by increasing IL-12 production. Life Sci 1999; 65: 2143-50.

[18] Musabak U, Sengul A, Oktenli C, et al. Does immune activation continue during an attack-free period in familial Mediterranean fever? Clin Exp Immunol 2004; 138: 526-33.

[19] Livneh A, Langevitz P, Zemer D, Zaks N, Kees S, Lidar T. Criteria for the diagnosis of familial Mediterranean fever. Arthritis Rheum 1997; 40: 1879-85

[20] Jimenez-Caliani AJ, Jimenez-Jorge S, Molinero P, et al. Dual effect of melatonin as proinflammatory and antioxidant in collageninduced arthritis in rats. J Pineal Res 2005; 38: 93-9.

[21] Kühlwein E, Irwin M. Melatonin modulation of lymphocyte proliferation and Th1/Th2 cytokine expression. J Neuroimmunol 2001; 117: 51-7.

[22] Maestroni GJ, Conti A. The pineal neurohormone melatonin stimulates activated $\mathrm{CD} 4+$, Thy-1+ cells to release opioid agonist(s) with immunoenhancing and anti-stress properties. J Neuroimmunol 1990; 28: 167-76.

[23] Inserra P, Zhang Z, Ardestani SK, et al. Modulation of cytokine production by dehydroepiandrosterone (DHEA) plus melatonin (MLT) supplementation of old mice. Proc Soc Exp Biol Med 1998; 218: 76-82.

[24] Shaji AV, Kulkarni SK, Agrewala JN. Regulation of secretion of IL-4 and IgG1 isotype by melatonin-stimulated ovalbumin-specific T cells. Clin Exp Immunol 1998; 111: 181-5.

[25] Sacco S, Aquilini L, Ghezzi P, Pinza M, Guglielmotti A. Mechanism of the inhibitory effect of melatonin on tumor necrosis factor production in vivo and in vitro. Eur J Pharmacol 1998; 343: $249-55$.

[26] Konakchieva R, Kyurkchiev S, Kehayov I, Taushanova P, Kanchev L. Selective effect of methoxyindoles on the lymphocyte proliferation and melatonin binding to activated human lymphoid cells. J Neuroimmunol 1995; 63: 125-32.

[27] Vijayalxmi A, Reiter RJ, Leal BZ, Meltz ML. Effect of melatonin on mitotic and proliferation indices, and sister chromatid exchange in human blood lymphocytes. Mutat Res 1996; 351: 187-92. 
[28] Sulli A, Maestroni GJ, Villaggio B, et al. Melatonin serum levels in rheumatoid arthritis. Ann N Y Acad Sci 2002; 966: 276-83.

[29] Cutolo M, Otsa K, Aakre O, Sulli A. Nocturnal hormones and clinical rhythms in rheumatoid arthritis. Ann N Y Acad Sci 2005; 1051: 372-81.
[30] Haase CG, Faustmann PM. Benign multiple sclerosis is characterized by a stable neuroimmunologic network. Neuroimmunomodulation 2004; 11: 273-7.

[31] Pena C, Rincon J, Pedreanez A, Viera N, Mosquera J. Chemotactic effect of melatonin on leukocytes. J Pineal Res 2007; 43: 263-9.

Received: May 2, 2010

Revised: September 12, 2010

Accepted: September 14, 2010

(C) Musabak et al.; Licensee Bentham Open.

This is an open access article licensed under the terms of the Creative Commons Attribution Non-Commercial License (http://creativecommons.org/licenses/by-nc/

$3.0 /$ ) which permits unrestricted, non-commercial use, distribution and reproduction in any medium, provided the work is properly cited. 